\title{
A Gustatory Repellent for Protection of Agricultural Land from Wild Boar Damage: An Investigation on Effectiveness
}

\author{
Adrian Schlageter (Corresponding author) \& Daniel Haag-Wackernagel \\ Integrative Biology, Department Biomedicine, University of Basel \\ Anatomisches Institut, Pestalozzistrasse 20, 4056 Basel, Switzerland \\ Tel: 41-61-276-2712Ｅ-mail: adrian.schlageter@unibas.ch
}

Received: November 25, 2011

Accepted: December 21, $2011 \quad$ Online Published: April 1, 2012

doi:10.5539/jas.v4n5p61

URL: http://dx.doi.org/10.5539/jas.v4n5p61

\begin{abstract}
Following the spread and increase of wild boar populations in Europe during the last decades, conflicts with humans have intensified also in Switzerland. Damage to crops and grassland augmented considerably and became unacceptable. Farmers and authorities are highly interested in efficient alternatives to the installation of costly and time consuming electric fences for crop protection. In the present study we investigated the effectiveness of a gustative repellent in field experiments with free-ranging wild boars in clover sowings, meadows, and wheat fields. Although we observed a slight trend towards a damage reduction, the results show, that the repellent was not able to prevent damage at a significant level. We further could not detect any area avoidance by the wild boars as a response to the repellent. On the basis of our findings we conclude that gustative repellents relying on learned avoidance as a consequence of negative experience are not a promising means for protection of crops and grassland from wild boar damage. We further discuss the effects of different agricultural crops and the anthropogenic influence on the frequency of damage.
\end{abstract}

Keywords: Crop protection, Crop damage, Gustatory repellent, SUCROSAN, Sus scrofa, Wild boar

\section{Introduction}

During the last three decades, populations of the wild boar (Sus scrofa) in Europe have increased remarkably and almost simultaneously and the species has spread into new areas over the entire continent. Following the spread and increase in population size, the wild boar extended its activity into agricultural land, which intensified conflicts with humans. Wild boars cause considerable damage to crops and grassland. In many European countries, governmental compensations for crop damage amount to millions of Euros every year (Mazzoni della Stella et al. 1995, Vassant 1997, Calenge et al. 2004). Since about 1970, the spread and size of populations have increased in Switzerland, which is manifested by continuously increasing wild boar bags. Accordingly, crop damage increased dramatically and became unacceptable to farmers and game authorities as compensation for wild boar damage to crops and grassland simultaneously increased (Geisser 1998). This is also true for the Canton Basel-Land in Northwestern Switzerland. The region suffers from high wild boar densities and high amounts of damage to agriculture.

Three methods dominate among the attempts to reduce wild boar damage that are recommended in many scientific and popular articles (Briedermann 1990, Breton 1994, Mazzoni della Stella et al. 1995, Vassant 1997, Geisser 1998). First, wild boars are hunted intensively to keep population densities low. Second, hunters offer supplemental food in the forest to keep the wild boars off the farmland. Third, farmers put up fences and other deterrent systems to prevent wild boars from entering the fields. Hunting proved to reduce wild boar damage (Geisser \& Reyer 2004). However, wild boar reproductive rates can increase up to $200 \%$ under ideal conditions and, therefore, populations can recover within one year (Briedermann 1990). The scientific debate on the effectiveness of supplemental feeding in terms of damage reduction is controversial. While some studies proved the method to be successful (Vassant \& Breton 1986, Meynhardt 1991, Vassant et al. 1992, Vassant 1994a, Vassant 1994b, Geisser 1998, Calenge et al.2004), others found no effect (Geisser \& Reyer 2004), or even showed supplemental feeding to enhance wild boar damage (Hahn \& Eisfeld 1998, Cellina 2008). The latter revealed considerable amounts of artificial food in the stomachs of shot wild boars of $40 \%$ and $50 \%$ respectively, concluding that supplemental feeding increases reproductive potential and therefore rather supports higher 
populations than reduces damage to crops by a dissuasive effect. In the Canton Basel-Land, supplemental feeding is exclusively practiced to bait wild boars for easier shooting.

Field protection is still essential for damage prevention. Farmers preferably protect vulnerable crops with electrical fences, which have been proven effective in preventing wild boars from entering the fields (Boisaubert et al. 1983, Vassant \& Boisaubert 1984). However, electrical fences require regular surveillance to assure maintenance of both fences and batteries, which is costly in terms of time. Additionally, electrical fences are expensive and the government does not provide financial support. In the Canton Basel-Land, reimbursement for fencing costs repeatedly exceeded compensation payments in the past years and was therefore disestablished in 2008. Farmers and authorities are therefore highly interested in efficient alternatives to the expensive and labor-intensive electrical fence. Several deterrents against wild boar have been investigated so far. Methods based on acoustic, gustatory, odor, and optic deterrence have not yielded satisfactory long-term results (Vassant \& Boisaubert 1984, Vassant 1994a, Schlageter \& Haag-Wackernagel 2011, Schlageter \& Haag-Wackernagel 2012). These methods include radios, PIR-activated horns, gas cannons, chemical treatment of corn seeds with several repellents, and solar-powered LED-blinkers. However, various deterrents are commercially available today that claim to be effective in protecting crops from wild boar damage. At present, there is little or no data to support claims of efficacy for the majority of these deterrent systems. Information on successful deterrence of wild boars mainly derives from the manufacturers of the deterrent systems themselves.

Since wild boars become nocturnal in areas where they are hunted, damage to agricultural land is exclusively caused during the night. A gustatory repellent might therefore be a promising alternative to the electric fence, because its deterrence effect does not rely on visibleness. Against this background, gustatory repellents are a promising means for deterring wild boar from agricultural land, not only crops but also meadows and pasture. A deterrent commercially available that particularly claims to deter wild boar is "SUCROSAN $®$ ". According to the manufacturer, the effectiveness of the repellent has been proved in an investigation in the field that was conducted by game wardens. However, these results have not been published and the company was not able to provide us with detailed information on the study in question. We therefore conclude this study rather to be an anecdotal report, which does not meet scientific criteria. However, local farmers have tested the repellent on their own and their positive reports have attracted the interest of game authorities of the Canton Basel-Land. In the present study we investigated the gustatory repellent "SUCROSAN ${ }^{\circ}$ " in field experiments with free-ranging wild boars with respect to the following objectives:

1a) Is the repellent effective in preventing agricultural land from being damaged by wild boars? 1b) Does the distance to the nearest occupied building (e.g. barnyard) have an effect on the frequency of damage events? 1c) Are there differences in effectiveness of the repellent between different cultures? 1d) Does the probability of wild boar damage change with the seasons? 2) Does the time-span between two consecutive damage events prolong conditionally on wild boars having eaten the gustatory repellent pellets?

\section{Materials and Methods}

\subsection{Study Area}

The present study was conducted in several areas of the Canton Basel-Land, a region in northwestern Switzerland. Our field experiments took place at 11 experimental plots, which were located in 5 municipal areas (Fig. 1). The Canton Basel-Land is situated in northwestern Switzerland and covers an area of $518 \mathrm{~km}^{2}$. The topography is hilly and ranges in elevation from $250 \mathrm{~m}$ to $1170 \mathrm{~m}$. The climatic conditions are continental with an average annual precipitation of $750-1300 \mathrm{~mm}$. Average temperatures range from $2.1^{\circ} \mathrm{C}$ in January to $19.6^{\circ} \mathrm{C}$ in July. Forests cover $42 \%$ of the study area, are patchy distributed, and are mostly used for the lumber industry. Agricultural land covers $41 \%$ of the area and consists mainly of pasture (50\%), cropland (40\%), and fruit- and winegrowing (10\%). Settlement and traffic infrastructure covers another $16 \%$ of the Canton's area. The landscape is characterized by a high structural diversity. Except for the lynx (Lynx lynx), natural predators of the wild boar are absent in Northwestern Switzerland.

\subsection{Repellent}

The gustatory repellent "SUCROSAN ${ }^{\circledR}$ " are food pellets on the basis of wheat and maize with phosphorous acid as the active ingredient $(\mathrm{Ph}$ value $=2)$. The detailed composition of the pellets was not communicated by the manufacturer. According to the manufacturer, these pellets should attract wild boars by its odor. Once wild boars have eaten the pellets the phosphorous acid would unfold its flavor. This being a disagreeable experience for the animals would lead to a future avoidance of the area by a learning effect. The gustatory repellent was available in $15 \mathrm{~kg}$-bags. Average weight of one pallet was $1 \mathrm{~g}$ giving a quantity of $15^{\prime} 000$ pellets per bag. Costs per kilogram was $€ 14$. 


\subsection{Experimental Design}

We performed field experiments in clover sowings, meadows, and wheat-cultures. The experimental plots were selected on the basis of the presence of at least one event of damage by wild boars during a pre-experimental phase of 30 days. In choosing this selection criterion we aimed at a higher chance of repeated damage events during our experiments. The acreage of experimental plots varied between $1700 \mathrm{~m}^{2}$ and $200000 \mathrm{~m}^{2}$. For each plot we recorded the distance to the nearest barnyard or other occupied building respectively (herein after referred to as barnyard). The duration of each trial on a particular experimental plot was 40 days. During the first 20 days the experimental plot was left untreated. After this initial pretreatment phase the experimental plot was treated with the gustatory repellent for another 20 days. Inspections of the experimental plots were performed every second day. At each inspection, new wild boar damage events were recorded. During the pretreatment phase we only recorded the damage events, during the following treatment phase we also recorded if the gustatory repellent pellets were eaten (removal) by wild boars or not. Pellet removal by wild boars was recorded by detecting tracks. Except for one case where pellets were removed by carrion crows (Corvus corone corone), wild boar tracks were clearly detectable in all other cases of pellet removal. According to the manufacturers advice, we treated the experimental plots with a quantity of some 5 pellets per $\mathrm{m}^{2}$. Because the gustatory repellent was only weather resistant to a certain degree, we refreshed the treatment every 10 days or immediately after pellet removal by wild boars.

\subsection{Statistical Analysis}

Objektives 1a) - 1d) were assessed by a generalized linear mixed model (GLMM). The binary indicator variable of a damage event was the dependent variable. The predictors of interest were "treatment" (SUCROSAN Yes/No), "culture", the interaction "treatment-culture", "duration" of the experiment, "season", and the distance to the "barnyard". The coefficient "site" was implemented in the model as a random factor to correct for the dependence of multiple measurements at the same site. Because samples per month were to small we aggregated the months in a two-level factor "season" with spring and summer (March - August) and fall and winter (September - February). Our logistic regression model had a binomial error distribution and as link function we used the logit link. We fitted the model with the glmer-function of the Ime4-package (Bates 2005) using the R 2.12.0 software for statistical computing (R Development Core Team 2010). We assessed significance levels of the terms of the model by simulating the a-posteriori distribution with the sim-function of the arm-package (Gelman \& Hill 2007). We started with a model including all predictors and then gradually removed the non-significant interactions from the model, leaving the main effects within it. We used Bayesian methods to assess parameter estimate uncertainties because this is recommended as the most accurate method for generalized linear mixed models (Bolker et al. 2008). As a consequence we report $95 \%$ credible intervals (CrI) instead of confidence intervals or classical p-values. The CrI gives the $95 \%$ range of the posterior distribution of the parameter, where the posterior distribution expresses our knowledge of the parameter after having looked at the data.

The influence of the gustatory repellent on the time-span between two consecutive damage events (objective 2) was assessed by a cox proportional hazard model. The dependent variable was the time-span between two damage events or between a damage event and the end of an experiment, the latter being treated as censored observations (i.e. minimal time). All analysis was performed using the $\mathrm{R}$ software for statistical computing.

\section{Results}

An overview of the numbers of damage events, numbers of removal events and the distances for our experimental plots is given in Table1. We recorded damage events in all of our experimental plots. During the pretreatment phase every plot was damaged at least once, whereas during the treatment phase four plots remained without damage. Overall we recorded 24 damage events during the pretreatment phase and 19 damage events during the treatment. Pellet removal occurred in $47.4 \%$ of all cases of damage during treatment.

We found a non-significant trend towards a lower frequency of damage events during the treatment phase (GLMM, $b=0.032$, CrI: $-2.549,0.068$ ). The results of the cox proportional hazard model confirm this finding (Fig. 2). We measured 8 out of 33 time-spans between two consecutive damage events and one out of 10 minimal times respectively where the pellets have been removed by wild. The gustatory repellent had no significant effect on the time-span between two damage events ( $\mathrm{LRT}=1.56, \mathrm{df}=1, \mathrm{p}=0.211$ ).

We found a significant positive effect of the distance to the barnyard on the frequency of damage events (GLMM, b=0.019, CrI: 0.0007, 0.011). Wild boars caused more damage when the experimental plot was situated more distant from a barnyard (Fig. 3). 
There was a trend towards differences in frequency of wild boar damage between the cultures (Fig. 4). The damage frequency was highest in meadows and lowest in clover sowings, though, these differences were not significant (GLMM, $b=0.046$, CrI: $-0.374,6.469$ ). Moreover, there was no significant difference in effect of the treatment on the frequency of damage events between the cultures.

We further found a positive trend in effect of the duration of the experiment on the frequency of damage events (GLMM, b=0.44, CrI: -0.009, 0.107). Damage frequency augmented with continuing experiment. In contrast, the season did not have an effect on the frequency of damage events.

\section{Discussion}

The gustatory repellent investigated in the present study did not have a significant effect on the frequency of damage events, nor did it prologue the time span between two consecutive damage events. According to the manufacturer, the gustatory repellent should work on two different sensory levels, an olfactory and a gustatory level. First, the repellent should allure or attract wild boars by its smell. Second, the pellets should deter wild boars from the treatment area by its acetous taste. A wide range of studies on olfaction in wild boar and other suids confirm the species' excellent sense of smell (Zeuner 1967, Altevogt 1972, Meynhardt 1978, Günterschulze 1979, Briedermann 1990). Based on the fact that olfaction plays a major role in foraging of wild boars, the olfactory attractiveness of the repellent investigated in our study is doubtable since the pellets were eaten in only $47.4 \%$ of all cases of damage during treatment.

The effectiveness of chemical deterrents against vertebrates is conditionally confirmed in literature (Jordan Jr. \& Richmond 1991, Milunas et al. 1994, el Hani \& Conover 1995, Engeman et al. 1995, Belant et al. 1998, Mason 1997, Mason 1998). However, the efficacy of repellents varies strongly, depending on the functionality of the deterrent, the species investigated, and the population densities of target animals. Repellents causing pain are considered more effective than those causing fear or sickness. The pain-causing sensory irritants are most effective when being directly applied to crops. On the other hand, there is no evidence in literature that sensory irritants effect targeted species to abandon areas. Animals usually do not learn to avoid treated foods. Repellents relying on taste are rarely, if ever, effective. Products that claim effectiveness solely because of an acetous taste are doing so in the absence of reliable evidence.

However, we found a slight trend that the gustatory repellent reduced the frequency of damage events. The manufacturer claims that the wild boars should be deterred by the acetous taste of the pellets and, moreover, should avoid the treatment area in the future as a result of a learning effect. We would therefore have expected to find a positive effect of the pellet removal on the time-span between two damage events. Since we could not prove such an effect, we would therefore interpret the result of the GLMM rather to be ascribed to an olfactorythan a gustatory effect. The trend towards a lower frequency of damage events on treated areas we observed may be based on cautious behavior of the wild boars confronted with an odor not used to. This could have been either the odor of the repellent itself or a disturbance caused by our presence during the treatments. In a previous study (Schlageter \& Haag-Wackernagel 2012) on the effectiveness of a fear evocating odor repellent we could, however, not show any neophobia or startle responses of wild boars.

The damage frequency was positively correlated with the distance of the experimental plot to the barnyard. This is in line with previous studies, which have revealed that wild boar damage is negatively correlated with the grade of anthropogenic influence (e.g. Schley et al. 2008). We think that the distance to the nearest occupied building (i.e. barnyard) was an accurate measure for remoteness of an experimental plot from human activity in the present study. Damage frequency was highest in meadows (trend: Fig. 3). This is in line with other studies that showed grassland to be damaged at higher proportions than cereal crops and other seasonal cultures (Schley 2000, Schley et al. 2008). Our result also corresponds with the yearly damage statistics of the hunting and fishing agency of the Canton Basel-Land, which amounts damage to grassland at approximately $50 \%$ of all damage caused by wild boars (unpubl. data).

\section{Conclusion}

We could show that the gustatory repellent "SUCROSAN $®$ " was ineffective in reducing damage to the experimental plots, regardless of the culture that was treated. The weak trend of lower frequency of damage events we observed during treatment could not be explained by any gustative repellency of the deterrent since the time-span between two consecutive damage events did not prolong during treatment compared to the pretreatment phase. We rather ascribe this trend to a general cautious behavior of the wild boars facing an unknown odor, which could have been either the odor of the gustatory repellent itself or the odor of the first author. However, the effect was small and not significant. We therefore conclude the gustatory repellent to be 
inefficient in deterring wild boars from agricultural areas. Taking further into account that the repellent is very costly, we clearly advise against the use of this product.

In the Canton Basel-Land, farmers receive compensation for wildlife damage only if their fields were adequately protected. We recommend that farmers should not be encouraged to use any deterrent systems other than electric fences, which have been proven effective in protecting crops. On the basis of the present study, we suggest that compensation payment policies should not be changed for the present.

Yet, the problem of wild boar damage to agriculture is far from being solved and, therefore, more effort in developing new repellents is needed. Wild boar populations will recover from losses by hunting within a short time also in the future. Thus, field protection will remain essential and the need for inexpensive alternative deterrents will last.

\section{Acknowledgments}

The present study was funded by the Volkswirtschafts- und Sanitätsdirektion of Basel-Land, the Federal Office for the Environment (FOEN), and the Freiwillige Akademische Gesellschaft (FAG). I. Bloch and D. Zopfi, head and deputy of the department Veterinär-, Jagd- und Fischereiwesen provided the gustative repellent and brought us into contact with farmers that recently suffered wild boar damage. A. Ochsenbein gave technical support and valuable input for the field experiments. We thank the farmers at our study sites for readily letting us perform our experiments on their land. F. Korner-Nievergelt calculated the GLMM and the cox proportional hazard model.

\section{References}

Altevogt, R. (1972). Zur Verhaltensökologie der Trüffelschweine des Perigords (AW-Frankreich). Wissenschaftliche Zeitschrift der Humboldt-Universität zu Berlin. Reihe Mathematik/Naturwissenschaften XXY, 4, 407-410.

Authors. Date. Evaluation of an odor repellent for protecting crops from wild boar damage. in prep.

Bates, D. (2005). Fitting linear mixed models in $\mathrm{R}$ - using the lme4 package. $R$ News - The Newsletter of the $R$ Project, 5, 27-30.

Belant, J. L., Seamans, T. W., \& Tyson, L. A. (1998). Predator urines as chemical barriers to white-tailed deer. Proceedings 18th Vertebrate Pest Conference, 18, 359-362.

Boisaubert, B., Bouldoire, J. L., \& Vassant, J. (1983). Bilan de cinq années d'expérimentation de protection des cultures par clôtures électriques dans le département de la Haut-Marne. Bulletin Mensuel de l'Office National de la Chasse, 68, 15-26.

Bolker, B. M., Brooks, M. E., Clark, C. J., Geange, S. W., Poulsen, J. R., Stevens, H. H., \& White, J.-S. (2008). Generalized linear mixed models: a practical guide for ecology and evolution. Trends in Ecology and Evolution, 24, 127-135. http://dx.doi.org/10.1016/j.tree.2008.10.008

Breton, D. (1994). La limitation des dégâts de sanglier par la pose de clôtures électriques dans le département de la Haute-Marne. Bulletin Mensuel de l'Office National de la Chasse, 191, (Numéro special). 96-100.

Briedermann, L. (1990). Schwarzwild. (3rd ed.). Berlin: VFB Deutscher Landwirtschafts-Verlag.

Calenge, C., Meillard, D., Fournier, P., \& Fouque, C. (2004). Efficiency of spreading maize in the garrigues to reduce wild boar (Sus scrofa) damage to Mediterranean vineyards. European Journal of Wildlife Research, 50, 112-120. http://dx.doi.org/10.1007/s10344-004-0047-y

Cellina, S. (2008). Effects of supplemental feeding on the body condition and reproductive state of wild boar Sus scrofa in Luxembourg. Dissertation, University of Sussex, Brighton, UK.

El Hani, A., \& Conover, M. R. (1995). Comparative Analysis of Deer Repellents. Pages 147-155 in Repellents in Wildlife Management Conference Proceedings, 8-10 August 1995, Denver, Colorado, USA.

Engeman, R. M., Campbell, D. L., Nolte, D., \& Witmer, G. (1995). Some recent research results on non-lethal means for reducing animal damage to reforestation projects in the western United States. Proceedings of the 10th Australian Vertebrate Pest Control Conference, 10, 150-154.

Geisser, H. (1998). The wild boar (Sus scrofa) in the Thurgau (northeastern Switzerland): Population status, damages and the influence of supplementary feeding on damage frequency. Gibier Fane Sauvage - Game and Wildlife, 15 (Special Number Pts 2 and 3), 547-554. 
Geisser, H., \& Reyer, H-U. (2004). Efficacy of hunting, feeding, and fencing to reduce crop damage by wild boars. Journal of Wildlife Management, 68, 939-946. http://www.bioone.org/doi/abs/10.2193/0022-541X\%282004\%29068\%5B0939\%3AEOHFAF\%5D2.0.CO\%3B2

Gelman, A., \& Hill, J. (2007). Data analysis using regression and multilevel/hierarchical models. Cambridge: Cambridge University Press. http://dx.doi.org/10.2277/052168689X

Günterschulze, J. (1979). Studien zur Kenntnis der Regio olfactoria von Wild- und Hausschwein. Zoologischer Anzeiger, Jena, 202 (3/4), 256-279.

Hahn, N., \& Eisfeld, D. (1998). Diet and habitat use of wild boar (Sus scrofa) in SW-Germany. Gibier Faune Sauvage, 15, 595-606.

Jordan, D. M., \& Richmond, M. E. (1991). Effectiveness of a vertical 3-wire electric fence modified with attractants or repellents as a deer exclosure. Proceedings of the Eastern Wildlife Damage Control Conference, 5 , 44-47.

Mason, J. R. (1997). Repellents in Wildlife Management. (447 pp.). Ft. Collins, CO: Colorado State University Press.

Mason, J. R. (1998). Mammal repellents: Options and considerations for development. Proceedings of Vertebrate Pest Conference, 18, 325-329.

Mazzoni della Stella, R., Calovi, F., \& Burrini, L. (1995). The wild boar management in a province of Central Italy. IBEX Journal of Mountain Ecology, 3, 188-191.

Meynhardt, H. (1978). Schwarzwildreport. Leipzig, Germany: Neumann-Verlag.

Meynhardt, H. (1991). Schwarzwild-Bibliothek 4. Wildversorgung, Trophäen und Schadensverhütung. Melsungen, Germany: Verlag Neumann-Neudamm.

Milunas, M. C., Rhoads, A. F., \& Mason J. R. (1994). Effectiveness of odour repellents for protecting ornamental shrubs from browsing by white-tailed deer. Crop Protection, 13, 393-397. http://dx.doi.org/10.1016/0261-2194\%2894\%2990056-6

R Development Core Team. (2010). R: a language and environment for statistical computing. Vienna, Austria: R Foundation for Statistical Computing.

Schlageter, A., \& Haag-Wackernagel, D. (2011). Effectiveness of solar blinkers as a means of crop protection from wild boar damage. Crop Protection, 30, 1216-1222. http://dx.doi.org/10.1016/j.cropro.2011.05.008

Schlageter, A., \& Haag-Wackernagel, D. (2012). Evaluation of an odor repellent for protecting crops from wild boar damage. Journal of Pest Science. DOI: 10.1007/s10340-012-0415-4

Schley, L. (2000). The badger Meles meles and the wild boar Sus scrofa: distribution and damage to agricultural crops in Luxembourg. Brighton, UK: University of Sussex.

Schley, L., Dufrêne, M., Krier, A., \& Frantz, A. C. (2008). Patterns of crop damage by wild boar (Sus scrofa) in Luxembourg over a 10-year period. European Journal of Wildlife Research, 54, 589-599. http://dx.doi.org/10.1007\%2Fs10344-008-0183-x

Vassant, J., \& Boisaubert, B. (1984). Bilan des expérimentations enterprises en Haut-Marne pour réduire les dégâts de sanglier (Sus scrofa) à l'encontre des cultures agrucoles. Smposium International sur le sanglier (International Wild boar symposium). F. Spitz, and D. Pépin, technical coordinators. Toulouse, France, pp. 187-199.

Vassant, J., \& Breton, D. (1986). Essai de reduction des dégâts de sangliers (Sus scrofa) sur blé (Triticum sativum) au stade laiteux par distribution de maïs (Zea mais) en forêt. Gibier Faune Sauvage, 3, 83-95.

Vassant, J. (1994a). Les techniques de prévention des dégâts de sanglier. Bulletin Mensuel de l'Office National de la Chasse, 191, 90-93.

Vassant, J. (1994b). L'agrainage dissuasif: résultats d'expériences. Bulletin Mensuel de l'Office National de la Chasse, 191, 101-105.

Vassant, J. (1997). Le sanglier en France: ces quinze dernières années. Bulletin Mensuel de l'Office National de la Chasse, 225, 32-35.

Zeuner, F. E. (1967). Geschichte der Haustiere. Munich, Germany: BLV-Verlag. 
Table 1. Numbers of damage events during pre-treatment, and treatment (including pellet removal events) and distances $[\mathrm{m}]$ to the Barnyard and the forest for each experimental plot

\begin{tabular}{|c|c|c|c|c|c|c|c|c|c|c|c|c|}
\hline \multirow{2}{*}{\multicolumn{2}{|c|}{$\begin{array}{l}\text { Culture } \\
\text { Experimental Plot }\end{array}$}} & \multicolumn{2}{|c|}{ Clover } & \multicolumn{8}{|c|}{ Meadow } & \multirow{2}{*}{$\frac{\text { Wheat }}{\text { W1 }}$} \\
\hline & & C1 & C2 & M1 & M2 & M3 & M4 & M5 & M6 & M7 & M8 & \\
\hline \multirow[t]{3}{*}{ Damage } & Pretreatment & 4 & 2 & 1 & 2 & 1 & 1 & 1 & 2 & 2 & 6 & 2 \\
\hline & Treatment & 4 & 2 & 0 & 0 & 1 & 0 & 1 & 0 & 6 & 2 & 3 \\
\hline & (Removal) & (3) & (2) & $(0)$ & $(0)$ & $(0)$ & $(0)$ & $(0)$ & $(0)$ & (2) & $(0)$ & (2) \\
\hline \multirow[t]{2}{*}{ Distance } & Barnyard & 530 & 800 & 125 & 170 & 170 & 350 & 230 & 440 & 375 & 400 & 600 \\
\hline & Forest & 100 & 25 & 10 & 10 & 20 & 5 & 10 & 10 & 5 & 5 & 5 \\
\hline
\end{tabular}

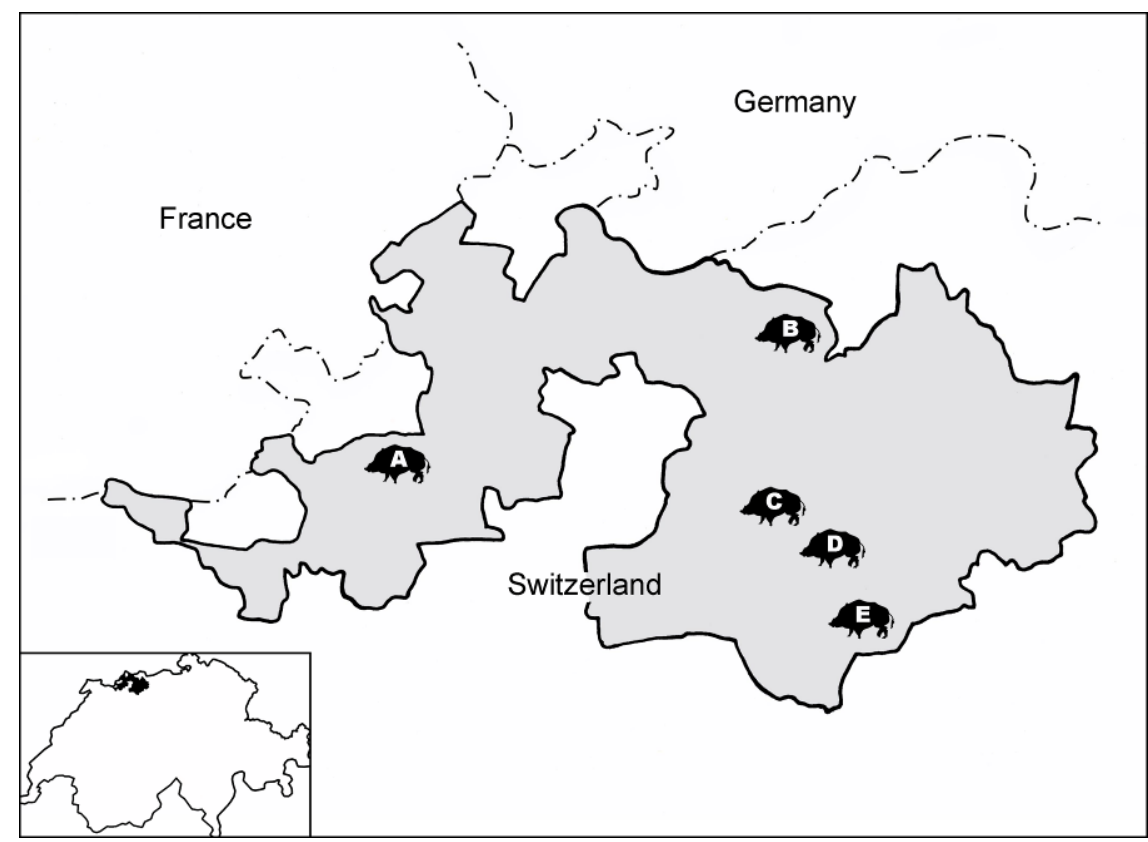

Figure 1. Location of the study sites. Grey: Canton Basel-Land, Switzerland. A = Blauen (5 experimental plots), $\mathrm{B}=\operatorname{Arisdorf}(1$ plot $), \mathrm{C}=$ Lampenberg (2 plots), $\mathrm{D}=$ Bennwil (1 plot), $\mathrm{E}=$ Eptingen (2 plots)

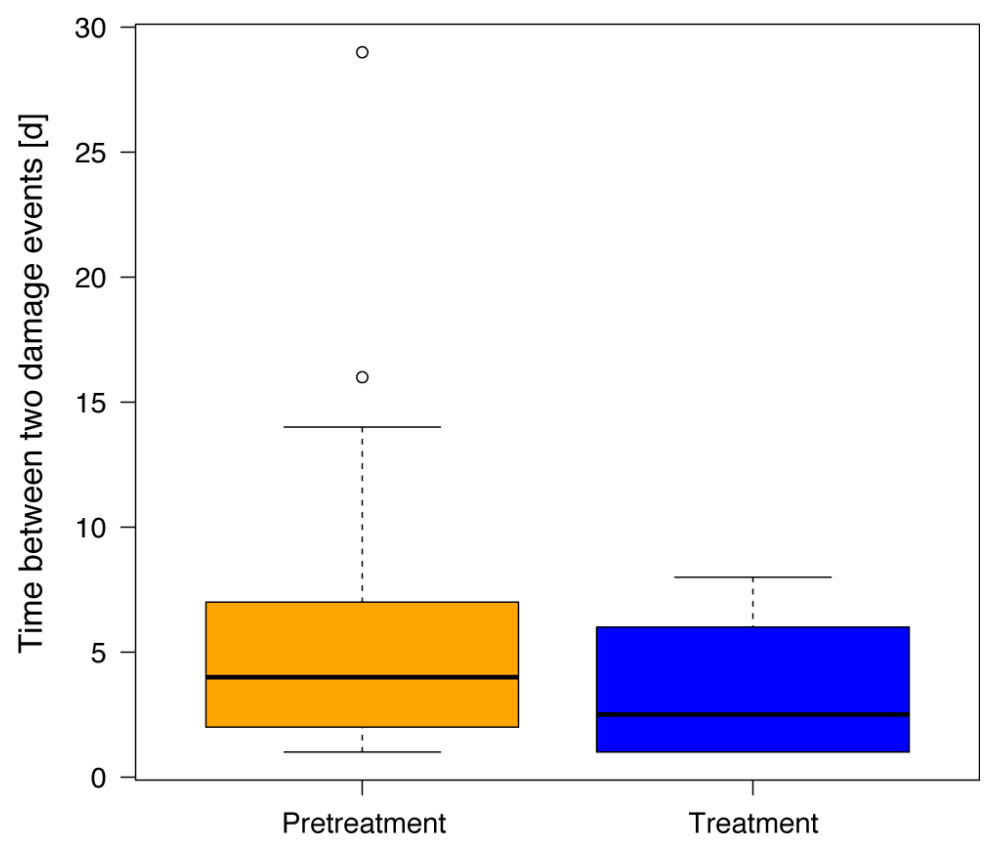

Figure 2. Time-span between two consecutive damage events for the pretreatment phase and the treatment phase 


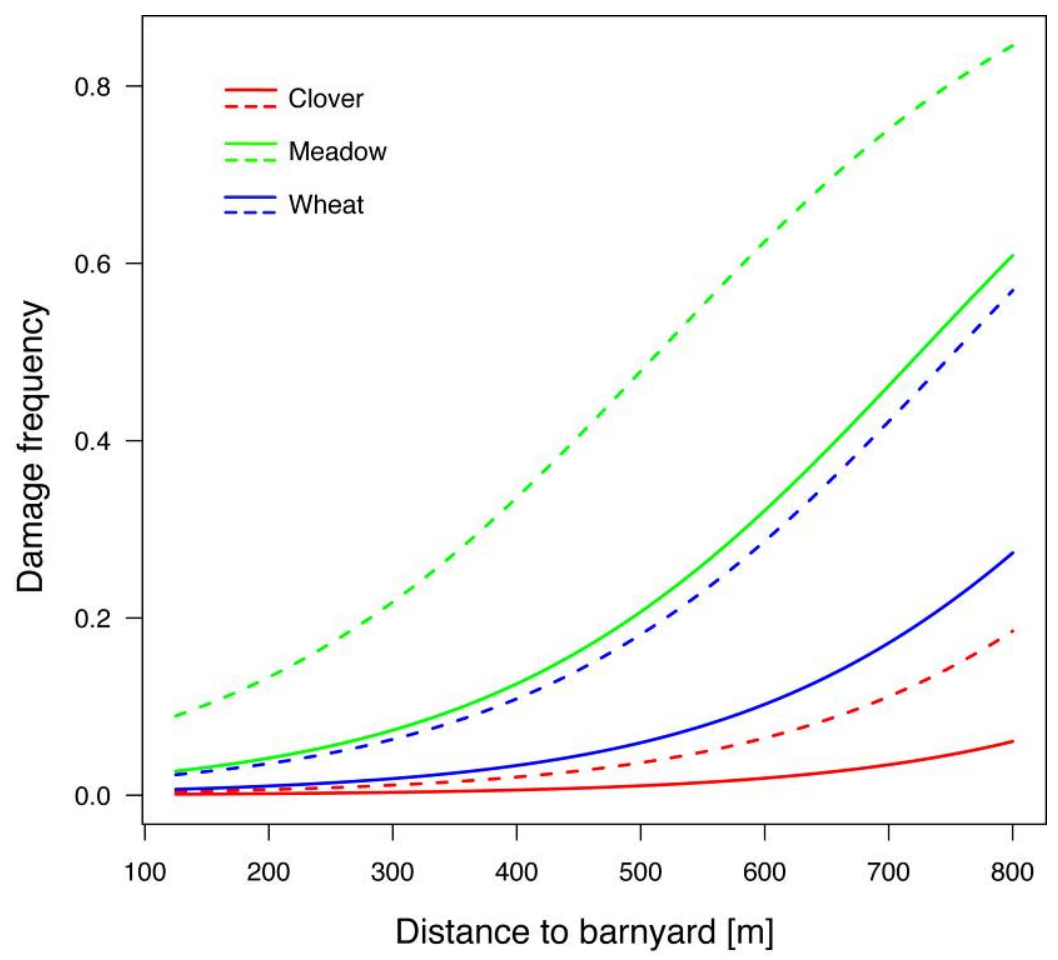

Figure 3. Influence of the distance between the experimental plots and occupied buildings (Barnyard) on the damage frequency for the three different cultures

Dashed lines: pretreatment, solid lines: treatment

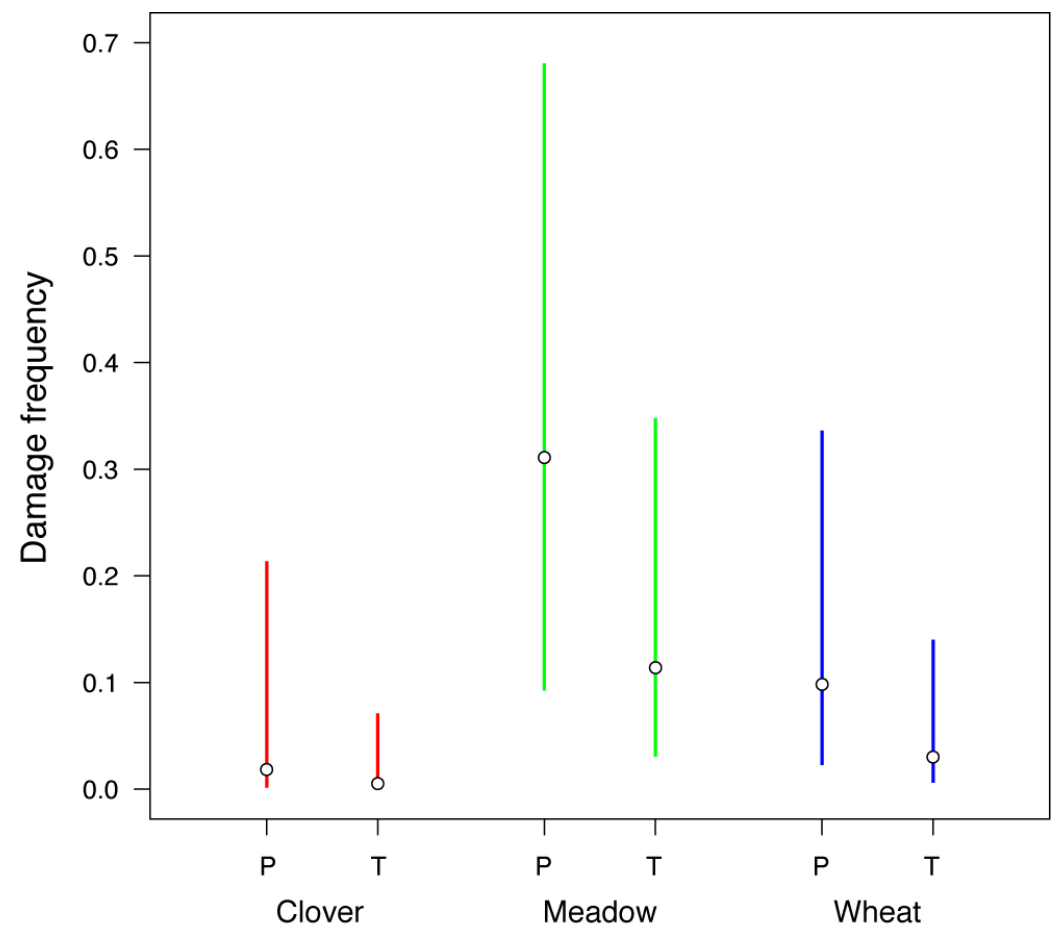

Figure 4. Difference in damage frequency between the cultures. $\mathrm{P}=$ pretreatment, $\mathrm{T}=$ Treatment 